\title{
Carlos Marichal, Steven Topik y Zephyr Frank (coords.), De la plata a la cocaína. Cinco siglos de historia económica de América Latina, 1500-2000. El Colegio de México/Fondo de Cultura Económica, México, 2017, 526 pp.
}

\author{
Joaquín Pinto* \\ 21 de marzo de 2018
}

A temática central de esta obra colectiva se hace por demás interesante ya que
propone la realización de una historia económica centrada en el análisis de
varios de los productos de exportación que integraron a América Latina al mer-
cado global, partiendo de la premisa que el proceso de globalización no sólo es
un fenómeno aparecido a comienzos de la década de 1990, sino que se presentó
como hecho de largo plazo, en que el continente americano es partícipe por lo me-
nos desde comienzos del periodo colonial. El enfoque empleado por cada uno de
los autores de esta obra se fundó en el concepto de cadenas de mercancías, donde
cada eslabón y sus partícipes tienen un papel fundamental en su desarrollo, lo que
involucró el estudio de productores, distribuidores y consumidores, tomando en
cuenta el papel del poder y el gobierno en sus configuraciones.
Este acercamiento permite que los trabajos (tal y como se plantean en las
conclusiones por los coordinadores) logren establecer un equilibrio entre una vi-
sión dependentista, que aduce un papel de victimización a las economías latinoa-
mericanas presas de la libre decisión del entorno externo, con el enfoque ortodoxo,
que plantea un desarrollo del mercado como fenómeno social neutral en el cual la
ley de la oferta y la demanda actúa de forma casi autónoma sobre los escenarios de
intercambio. Este logro se debe al tratamiento de cinco aspectos que son centrales
en el desarrollo de la obra y que pasaremos a describir, no sin antes aclarar que

\footnotetext{
*Universidad del Tolima, Ibagué, Colombia. Email: josejoaqo@yahoo.com. ORCID: 00000003-0791-4043
} 
se abordará cada uno de ellos enfatizando su presencia en capítulos específicos, lo cual no indica que estén ausentes en los restantes; por el contrario, son ejes trasversales que se encuentran inmersos en el desarrollo de cada uno de ellos.

El primer aspecto se refiere a la falsa idea de otorgar a los países productores de materias primas un papel pasivo frente a la determinación de las pautas de consumo y la fijación de precios. Tal es el caso del tabaco, producto que es analizado por Laura Náter, cuyo trabajo advierte del aumento de la demanda del mismo y el cambio de los patrones de consumo ocurridos en Europa como producto de la expansión de su producción en América durante el periodo colonial, lo que llevó incluso al Estado español a la consolidación del monopolio y su posterior desaparición debido a la falta de caudales para su mantenimiento después de la guerra de independencia. Un fenómeno similar es estudiado por Steven Topik y Mario Samper, ya que Brasil trasformaría las pautas de consumo del café a través de un importante crecimiento de la oferta, lo que provocó la caída de los precios y permitió un mayor acceso a la bebida a los sectores populares de países compradores, de allí que los productores fuesen capaces de fijar los precios y crear instituciones comerciales encargadas de su distribución, tal y como también aconteció en Costa Rica. A la postre, los autores muestran la forma en que el control del mercado pasó paulatinamente de los productores a multinacionales de integración vertical. De la misma forma, Zephyr Frank y Aldo Musacchio demuestran cómo Brasil no fue una víctima del mercado en la producción cauchera con su rápido auge y caída, debido a que no pudo establecer un sistema de producción a gran escala con bajos salarios, razón por que perdió competitividad en los mercados externos. Estos ejemplos dan cuenta de uno de los principales aspectos del libro, la participación activa de los productores al determinar la demanda de los productos gracias a la trasformación de las pautas de consumo, con base en el aumento de la producción y la popularización de su disfrute.

El segundo aspecto se refiere a la constatación de que el aumento de demanda afectó la vida de los países productores y de los consumidores europeos. Esto es claro al indagar sobre la exportación de plata estudiada por Carlos Marichal, quien describe los principales actores que jalonaban la demanda del metal, lo que obligó a toda una compleja red de organización del mundo americano, alrededor de la producción de monedas y la búsqueda de mano de obra y capital, a la extracción de la codiciada plata; proceso que llegó a determinar la circulación interna en el nuevo mundo, así como la extracción con destino a Europa y Asia. Si bien la independencia significó un breve paréntesis y los cambios en los patrones monetarios afectaron la producción, Marichal muestra la forma en que México se adaptó a la demanda producida por los nuevos usos del metal durante el siglo XIX. Otro ejemplo del impacto amplio que tiene la variación de la demanda lo desarrollaron Rory Miller y Robert Greenhill, quienes demuestran, a través de una historia conjunta de la producción de guano y nitratos, cómo Perú y Chile 
respondieron al incremento de la demanda de fertilizantes como producto del crecimiento poblacional y la obligación de los países para satisfacer las necesidades básicas de consumo alimenticio, este trabajo resalta la importancia de estudiar la incidencia del Estado en el manejo del mercado, el espacio de maniobra de los capitalistas locales en América Latina y del sector financiero interno y externo para la compresión de los fenómenos exportadores.

El tercer aspecto hace hincapié en la compresión de los mercados como constructos humanos determinados por valores, instituciones sociales, económicas y políticas. Casi en todos los capítulos esta noción es constante y se constituye en pieza clave para dar respuesta a perspectivas que entienden el mercado como fenómeno autorregulado. Debido a la bastedad del ítem, me permitiré hacer mención de un factor poco advertido por los historiadores económicos al reflexionar sobre el desarrollo de las exportaciones, me refiero al ámbito cultural, que es clave para la determinación de la demanda que trasforma los entornos productivos de dos materias primas: el índigo y la grana cochinilla. Para el primero de estos productos, David MacCreery demuestra cómo los patrones de consumo del tinte azul variaron al entrar en contacto ambos mundos, el nuevo y el viejo, ello a través de tres experiencias como lo fueron Carolina del Sur, Centro América y Bengala, lo que le permitió constatar cómo la tierra, la fuerza de trabajo, la inversión de capital o el conocimiento técnico no significaron el deterioro de la producción, sino la aparición de tintes sintéticos. A la postre, la demanda de índigo se recuperó debido al ambiente cultural del siglo XX, donde su principal debilidad (su tendencia a desvanecerse) colmó las expectativas de consumidores jóvenes en todo el globo. Por otra parte, la grana cochinilla era de suma importancia y su demanda se centraba más en la durabilidad del tinte y el valor simbólico del rojo como tonalidad fundamental para la expresión del estatus social, es así como Oaxaca se convirtió durante el periodo colonial en el principal centro de producción de los terrones que tendrían como destino teñir las ropas de príncipes y prelados, cadena que funcionaba con una fuerte dependencia del crédito mercantil colonial, llegando a constituirse en un semimonopolio, como lo demuestra Carlos Marichal. Así, ambos capítulos dan cuenta de un fuerte impacto del aspecto cultural sobre las cadenas de mercancías, debilitando una postura que sostiene la autodeterminación de los mercados casi sin intervención de la voluntad humana.

En un cuarto ámbito encontramos la necesidad de desarrollar una historia social de las materias primas. Cada una de las investigaciones del volumen da cuenta de un elaborado trabajo cuantitativo, pero avanzan más allá de lo que indican las cifras a través de la indagación de los fenómenos sociales y políticos que afectaron la conformación, funcionamiento y desaparición de las cadenas de mercancías. De esta forma para el caso de Bahía y su producción de cacao abordada por Mary Ann Mahony, encontramos una constelación de elementos que fueron centrales para que los productores asumieran la decisión de emprender la explota- 
ción de este bien agrícola, tales como el entorno ambiental, la política maderera, la disposición de mano de obra y la demanda internacional. Otro tanto encontramos en el trabajo de Horacio Crespo sobre el azúcar, en el cual se hace un completo análisis de las estrategias llevadas a cabo para la promoción o ataque de subsidios a la producción de remolacha como firme competidora de la caña en detrimento de la producción latinoamericana, en el trabajo se observa la forma en que múltiples sectores se vieron inmiscuidos en dicha confrontación y cómo estos se adaptaron a las condiciones cambiantes. De nuevo un interesante enfoque emerge del trabajo sobre el banano, elaborado por Marcelo Bucheli e Ian Read, en el cual se centran en el papel fundamental desempeñado por la United Fruit Company como firma encargada de la trasformación de los hábitos de consumo en Estados Unidos, llegando a consolidar un gran dominio al maniatar al gobierno federal para su juzgamiento debido al amplio poder que desempeñaba para los intereses hemisféricos, situación que cambiaría posterior a la segunda guerra mundial como producto del mejoramiento de las técnicas de conservación de fruta fresca, el ataque de la prensa y la presión del departamento de justicia sobre la otrora todo poderosa compañía.

Por último, sobresale la función de la oferta, el consumo y el sector intermediario al abordar la historia del comercio de materias primas. Este punto es ilustrado por Allen Wells, cuyo trabajo da cuenta de todos los puntos de la cadena en torno a la producción del henequén, fibra que ocupó un papel central en Yucatán, pero debido a la segmentación del mercado por la aparición de nuevas fibras terminó por sucumbir. Dicho capítulo, además de presentar un completo estudio de la cadena de mercancías, advierte la situación actual de la región con una amplia descripción de sus problemas sociales. Asimismo, Paul Gootemberg nos ofrece una mirada completa de la producción de coca y de cocaína previo a que su tráfico, transporte, distribución y consumo coparan las portadas de los diarios a nivel mundial, reportando la tragedia propia de su manifestación. El autor, desde una perspectiva completa, muestra cómo pasó de una hoja de consumo ritual a ser un fármaco con distintas utilidades para el mundo occidental, lo que modificó su producción y sus redes de distribución hasta los años cincuenta del siglo XX.

Este breve recuento, más allá de hacer una síntesis apretada de cada capítulo, nos permite visualizar los cincos ejes expuestos en cada uno de los trabajos y cómo los atraviesan en su propia constitución. Así, la obra no sólo invita a un lector ávido del conocimiento del devenir de la historia económica de América Latina por medio de su integración al sector externo, sino que en su función formadora, invita también al desarrollo de estudios que a futuro indaguen sobre otras mercancías tomando en cuenta todos los componentes inmersos en su desarrollo, es decir, producción-distribución-consumo, como un todo en donde ninguna de las partes tiene la total preponderancia para la determinación de la oferta o la demanda durante todo un periodo de desarrollo. Contrario a ello, el libro demuestra 
que las cadenas de mercancías se desempeñan como constructos cambiantes en el tiempo y en donde sus distintos componentes, inmersos en una marcada competencia, ocupan el papel protagónico de manera secuencial y en algunos casos simultánea. Igualmente, los trabajos rescatan la incidencia de los Estados, empresas, comunidades y entidades financieras en la determinación de las características del mercado, en donde ninguno de ellos puede ser considerado como un factor pasivo que recibe los estímulos del exterior, sino que toma decisiones de acuerdo con la información con la que disponen.

En esta línea es menester plantear tres aspectos que el texto deja en el vacío. Por fortuna este volumen se muestra incompleto ya que permite a futuro la realización de nuevas indagaciones sobre algunos aspectos que no se encuentran, como el desarrollo de las cadenas de mercancías en torno al petróleo (señalado por los coordinadores en las conclusiones). Igualmente, sobresale la ausencia de un conjunto de países que se integraron al mercado externo con sus propias cadenas como lo fueron Argentina, Uruguay, Colombia, Ecuador y Venezuela; países para los cuales el texto debe ser sugerente para la elaboración de similares aportes. Ciertamente la obra indica que los trabajos escapan a un enfoque nacional, en algunas ocasiones recae en él, se olvida la configuración de regiones que al menos en los casos faltantes constituyen el Cono Sur y el norte de los Andes. Otro aspecto poco tratado por los trabajos se refiere al estado actual de los lugares productores de aquellas materias primas que se insertaron en el mercado, lo cual pudiese dar luces sobre los resultados a largo plazo de la inserción. Aunque se recalca el papel activo que algunos capitalistas tuvieron en la generación de inversión, no se especifica si la misma sólo se orientó hacia el sector extractivo o si se involucró con otros sectores que a largo plazo se mantuvieron. De la misma forma, aunque con gran detalle se establece la actuación del Estado en la determinación de las cadenas de mercancías, poco se explora sobre el impacto de las mismas en la consolidación de los proyectos de fortalecimiento gubernamental, ya que es conocido que todo auge externo significaba un incremento de los ingresos aduaneros, mismos que fueron la principal fuente de financiamiento de los gobiernos vía impuestos a las importaciones, lo que contribuyó en algunos casos a la inversión pública que aún impacta sobre las comunidades beneficiadas, o a la reestructuración de sus obligaciones financieras en el exterior.

Más allá de estos faltantes, que se convierten en vetas de indagación que emergen gracias a esta obra, la obra se convierte en carta de navegación de futuras investigaciones ya que tiende puentes entre las versiones ortodoxas y dependentistas de la inserción de América Latina al mercado mundial, ofrece una visión de conjunto en donde productores-consumidores-intermediarios cumplen con un papel activo al prefigurar las cadenas de mercancías, invita a la indagación regional más allá de las barreras nacionales, incluye en sus análisis factores algunas veces matizados por otras tradiciones historiográficas al momento de indagar sobre esta 
clase de problemáticas, como la práctica del poder, la cultura y la organización social. Por último, el texto invita a la exploración de otras cadenas en similares contextos o en regiones que no fueron tratadas en el volumen. En síntesis, un compendio unificado, coherente y riguroso que enseña otras formas de confrontar la realidad material del continente y pone de relieve aspectos que antes fueron ignorados. Sin duda alguna, un gran aporte a las historiografías de cada región y de América Latina. 